\title{
Comunicación, educación y género: una perspectiva crítica para el análisis de experiencias territoriales
}

Comunicação, educação e gênero: uma perspectiva crítica para a análise de experiências territoriais

Comunicação, educação e gênero: uma perspectiva crítica para a análise de experiências territoriais

\section{María Emilia SAMBUCETTI}

Universidad Nacional de La Plata, Argentina / maie_16@hotmail.com

Florencia ACTIS

Universidad Nacional de La Plata, Argentina / florenciactis@gmail.com

Eleonora SPINELLI

Universidad Nacional de La Plata, Argentina / eleonoraspinelli@gmail.com

Chasqui. Revista Latinoamericana de Comunicación

N.o 135, agosto - noviembre 2017 (Sección Monográfico, pp. 197-214)

ISSN 1390-1079 / e-ISSN 1390-924X

Ecuador: CIESPAL

Recibido: 22-05-2017 / Aprobado: 31-08-2017 


\title{
Resumen
}

La comunicación/educación se alía a la perspectiva de género para ampliar su reto epistemológico, sus campos sociales de implicancia y sus horizontes políticos de transformación. Tomando prestada la potencia de esta articulación emergente y la dilución de sus fronteras disciplinarias, en tanto clave para re-leer el mundo, el artículo pone en diálogo y analiza los sentidos acerca de "lo educativo" presentes en dos espacios de taller, inscriptos en contextos sociales e institucionales disímiles. En primer lugar, el Taller de Comunicación, Arte y Género en la Unidad Penitenciaria Femenina No8 de Los Hornos, ciudad de La Plata; en segundo lugar, la Escuela Popular de Género, en la localidad de Ensenada.

Palabras clave: comunicación; educación; género, interpelación; cárcel; EPG.

\begin{abstract}
Communication and education are aligned to the gender perspective to expand its epistemological challenge, its social fields of implication and its political scope of transformation. By borrowing the power of this emergent articulation and dilution of their disciplinary boundaries, as a key to re-reading the world, the article puts into dialogue and analyzes the senses about "the educational" present in two workshop spaces, inscribed in dissimilar social and institutional contexts. Firstly, the Communication, Art and Gender Workshop at the 8th Female Penitentiary Unit of Los Hornos, city of La Plata; secondly, the Popular School of Gender, in the town of Ensenada.
\end{abstract}

Keywords: communication; education; gender, interpellation; prison; EPG.

\section{Resumo}

Comunicação/educação está aliada à perspectiva de gênero para expandir seu desafio epistemológico, área social de envolvimento e horizontes políticos de transformação. Usando o poder desta articulação recenté e diluição de suas fronteiras disciplinares como uma chave de releitura o mundo, o artigo coloca em diálogo e analisa os sentidos sobre o presente "educacional" em dois espaços, inscrito em diferentes contextos sociais e institucionais. Primeiro, o curso sobre Comunicação, Arte e Gênero na 8a Unidade Penitenciária Feminina de Los Hornos, cidade de La Plata; em segundo lugar, a Escola Popular de Gênero, na cidade de Ensenada.

Palavras-chave: comunicação; educação; gênero; interpelação; cárcere; EPG. 


\section{Introducción}

En este artículo nos proponemos mirar la sutura entre comunicación, educación y género durante el desarrollo de prácticas educativas en distintos territorios. Puntualmente, enlazamos dos experiencias de taller que tuvieron lugar en escenarios sociales disímiles, y relevamos/relacionamos aquellos sentidos sobre "lo educativo" presentes en cada una de ellas. Por un lado, el Taller de Comunicación, Arte y Género en la Unidad Penitenciaria Femenina Nro. 8 de la localidad de Los Hornos; por el otro, la Escuela Popular de Género (EPG), un proceso de educación popular con mujeres cooperativistas en la localidad de Ensenada. Nos centraremos en rastrear y pensar relacionalmente el lugar simbólico que ocupa 'lo educativo', explicitado no sólo en enunciados y palabras, sino también a través de las corporalidades, las emociones, los modos de valoración del tiempo y el espacio de taller, etc.

Nos interesa articular estas dos experiencias en tanto se reconoce a las mujeres participantes de las mismas atravesadas por una doble vulnerabilidad social, dada por su situación de clase y de género. Provenientes de extractos socio-económicos bajos, se trata mayormente de mujeres que no han culminado sus trayectos escolares y que han padecido distintas formas de precarización laboral, viendo quebrantados sus derechos constitucionales a la educación y el trabajo. Pero también, a causa de su condición de mujeres, experimentan otra dimensión de la desigualdad: están o han estado al cuidado de personas mayores y/o menores de edad, han debido resignar eventuales proyectos personales por trabajar dentro de su hogar y, sobre todo, han sufrido diferentes modalidades de abuso y violencia de género. En este sentido, se torna interesante profundizar en las representaciones, concepciones y experiencias comunes/diferenciales que traen consigo respecto de "lo educativo", y de qué modo las mismas se ven interpeladas -o no- luego de su paso por los talleres.

\section{Coordenadas teórico-conceptuales. De dónde partimos y hacia dónde vamos}

La mirada analítica sobre las experiencias que se narran y se recrean en el presente escrito, parten de la fusión tensa entre los campos de comunicación, educación y género, poniendo el énfasis en este último como dimensión transversal y base epistemológica.

Para empezar a desandar estas tensiones tomamos las palabras de Jorge Huergo, quien describe dos tipos de representaciones sociales hegemónicas en relación a lo que entendemos por lo educativo. Por un lado, aquellas que sacralizan a la educación, abstrayéndola de cualquier determinación material. Los procesos educativos suelen verse más o menos estables en el tiempo, invariables en su definición y cargados de positividad, es decir, de valores y prácticas 'posi- 
tivas' socialmente. Mientras que por otro lado, cobran fuerza perspectivas que han ligado de manera necesaria y casi excluyente a la educación y lo educativo con los procesos de transmisión de conocimientos que se viven en una institución: la escuela (2003, p. 1).

Se toma como eje de análisis para pensar "lo educativo" la ruptura de la premisa que lo relaciona inexorablemente con la escuela, o con 'lo académico' como únicos espacios habilitados para desarrollar procesos de formación. Siguiendo los planteamientos de Rosa Nidia Buenfil Burgos, entendemos la educación en sentido amplio, como toda instancia de modelización de sujetos/as sociales y políticos (1992, p. 16); de interpelaciones, en tanto llamamientos al individuo a convertirse en sujeto. La educación asume pues un sentido "neutro" en términos ético-políticos, y se disloca de sus instituciones tradicionales para emplazarse en diversos ámbitos sociales, incluso al interior del ámbito penitenciario, pese a lo "polémico" que resulte emplear el concepto de "educación" para mirar un contexto donde se violan a diario derechos humanos fundamentales.

A lo largo del artículo, el espacio carcelario será entendido como un sistema que procura, mediante determinadas técnicas y procedimientos rutinarios, formar-educar activamente un tipo de sujeto social, devenido en un 'otro/a animalizado/a. "El poder penitenciario penetra en los cuerpos y las subjetividades de las personas detenidas, en su cotidianeidad [...] es una 'maquinaria de órdenes' cuyo objetivo es la construcción de una subjetividad sumisa y subordinada" (Daroqui, 2014, p. 207). A su vez, la cárcel de mujeres en particular es tomada como una institución de castigo y violencia por razones de género, pero fundamentalmente como un régimen de vida que imprime una determinada bio-política del cuerpo; una "re-educación" del género y la sexualidad.

En cuanto a los talleres analizados, además de su condición educativa, son reconocidos como prácticas de comunicación que, insertas en la arena cultural, se constituyen en momentos de disputa, negociación, conflictos y acuerdos en el orden del sentido (Cremona, 2013, p. 11). Desde esta perspectiva eminentemente política, y lejos del sesgo instrumentalista, la comunicación es concebida en su intrínseca opacidad y ambigüedad teórica, metodológica. En palabras de Jesús Martín Barbero:

La primera necesidad es desplazar el concepto de comunicación atrapado en la problemática de los medios, los canales y los mensajes, al concepto de cultura [...] que nos permita pensar los nuevos procesos de socialización. $(2012$, p. 80)

Uno de los desafíos de la articulación entre comunicación, educación y género es revisar los sentidos que ha producido la cultura en torno a las mujeres, y que profundizan sus lugares de subalternidad. Estos sentidos, entramados en procesos de socialización, han articulado y consolidado a lo largo del tiempo no sólo un concepto de mujer, sino también de sexualidad femenina. "Tal perspectiva implica desmarcarse de los criterios que hacen de la sexualidad una invaria- 
ble, para sostener la problemática del deseo, de las prácticas eróticas-amatorias y las formas de subjetividad que se construyen como parte del campo socio-histórico" (Fernández \& Siqueira Peres, 2013, p. 18).

Por lo tanto, el género es en sí mismo un concepto móvil que estamos reelaborando críticamente en nuestra vida cotidiana. Cada vez que hablamos de género hablamos de poder (Cremona, 2016, p. 2). De las tramas de poder impresas de hecho a partir de normativas o pautas culturales sujetas a la identificación sexual que las instituciones hacen de las personas, y que las personas hacen de sí mismas enmarcadas en procesos históricos. En esta misma línea, Joan Scott lo define como "la forma primaria de relaciones significantes de poder" (1996, p. 289), en tanto ordena un modo de hacer política, de distribuir recursos, de producir conocimientos. Nada más y nada menos que por ello ponemos en valor de cara a nuestro análisis una mirada crítica de género, entendiendo que es el punto nodal para potenciar nuestras prácticas sociales, educativas y comunicacionales "alternativas"; pero también para seguir de-construyendo las relaciones significantes que reproducen las instituciones.

\section{El artesanado metodológico}

Una investigación social se constituye en algún punto como un proceso artesanal, "un artefacto hecho pieza por pieza" (Ortiz, 2004, p. 12) que implica hilvanar técnicas y recursos a miradas ético-políticas, de manera estratégica y situada. "Es una verdadera aventura metodológica, donde hay necesidad de exploración, de creatividad y de rigor" (Vassallo de Lopes, 2012, p. 22). En cuanto a la construcción de la metodología no se restringe al trazado de métodos y técnicas ni se circunscribe al momento inicial del proceso investigativo, sino que pone en juego ineludiblemente una dimensión epistemológica y teórica que orienta la toma constante de decisiones y de opciones. Se trata de "una concepción no-tecnicista y no-dogmática de la metodología como trabajo que prohíbe la comodidad de una aplicación automática de procedimientos aprobados y exige que toda operación dentro de la investigación deba cuestionar a la misma" (Vassallo de Lopes, 2012, p. 25). Cada investigación, debe configurar una estrategia metodológica acorde a sus particularidades.

En nuestro caso, partimos de un método cualitativo, de un modo de hacer cualitativo, clarificando nuestros objetivos de investigación vinculados a la interpretación de experiencias subjetivas; "al glose de los puntos de vista de los actores y su construcción de la realidad" (Sautu, 2005, p. 10). Pero también la propia reflexión sobre los procesos de acercamiento al campo y las interacciones que se establecen con "los actores", en este caso los grupos de mujeres, constituyen en sí mismas un objeto para el análisis. Los trabajos de campo que realizamos se identifican con un modelo etnográfico, en tanto observamos y describimos los contextos sociales de intervención intentando dar cuenta de sus principa- 
les problemáticas y estructuras de significación. Este modelo supone una presencia sostenida en el territorio, ya que se requiere "un modo de participación que permita crear relaciones cercanas favorables a la recogida de datos fiables que de otro modo serían difíciles de obtener, pero sobre todo, de comprender" (Álvarez Álvarez, 2008, p. 4).

Tanto en el caso de la EPG como en el caso del Taller en la Unidad Penitenciaria, se realizó un trabajo de adentramiento al mundo simbólico de las mujeres a través de la técnica de recolección de datos conocida como Observación Participante (OP), rótulo que según Rosana Guber peca de "ambiguo, impreciso y abierto" (2011, p. 65). Para la antropóloga argentina, esta "técnica" no puede ni debe ceñirse a un momento puntual e inicial de observación, sino transversalizar la práctica de campo. Tampoco se trata de una observación aleatoria, sino orientada y enfocada a los objetivos de investigación esbozados.

En ambos casos se complementó la OP con el desarrollo de talleres, entendidos como espacios estratégicos para la expresividad de los sujetos y la enunciación de sus realidades sociales pero también como instancias propicias para la construcción colectiva de conocimientos.

Se podría decir que el taller en la concepción metodológica de la educación popular es un dispositivo de trabajo con grupos, limitado en el tiempo y realizado con determinados objetivos, permitiendo la activación de un proceso pedagógico sustentado en el protagonismo de los participantes, el diálogo y la producción colectiva de aprendizajes, operando una transformación en las personas y respecto de la situación de partida. (Cano, 2012)

Se buscaron generar condiciones para la democratización de la palabra, poniendo en juego de manera prioritaria el capital simbólico, experiencial e idiosincrático, proveniente de su día a día y no del saber experto. En términos de Guber, aquellos conceptos experienciales (2011, p. 74) que organizan la subjetividad y materialidad de su universo cotidiano. Sin embargo, el taller involucra no sólo momentos de reflexión y aprendizaje mediante el uso de la palabra, sino también mediante la puesta en movimiento del cuerpo, disponiéndose como "un proceso de acción-reflexión-acción que los sujetos hace desde su realidad, desde su experiencia, desde su práctica social, junto con los demás” (Kaplún, 2002, p. 45).

Los talleres se construyeron como instancias esencialmente dialógicas. Desde la teoría freireana reconocemos en el diálogo un acto creador, "es el encuentro de los hombres que pronuncian el mundo, por tanto, no puede existir una pronunciación de unos a otros" (Freire, 1986, p. 72). Se recupera la politicidad del diálogo y su irreductible potencial de transformación, justamente porque es en el intercambio de saberes que se están dinamizando saberes, en tanto nuevos modos de lectura y comprensión del mundo. Según Claudia Korol, educadora popular y feminista, el diálogo no sólo se alimenta de la enunciación de 
palabras, sino también de la enunciación de los cuerpos, de la condición comunicativa y significante de los mismos, asumiendo "una pedagogía que parte de los cuerpos para pronunciar palabras, recuperando el valor de la subjetividad en la creación histórica, y criticando, una y otra vez, las certezas del punto de partida" (Korol, 2007, p. 18).

\section{Comunicación y Arte en una cárcel de mujeres}

El Taller de Comunicación, Arte y Género ${ }^{1}$ tuvo lugar los días viernes de 10 hs. a 13 hs. en el "Artículo 100" o "módulo" -como le llaman en la jerga penitenciariade la Unidad N8, situada en el barrio La Mecánica de la localidad de Los Hornos, distrito La Plata. La creación del módulo se enmarca en el programa "Casas por cárceles” (2011), y consiste en una edificación separada físicamente de la unidad penal. Destinado al alojamiento de presas en situación de pre-egreso, es decir, que hacen usufructo del derecho al régimen abierto; este lugar cuenta con tres habitaciones, cocina pequeña, salón comedor (donde se llevó a cabo el Taller), baño tipo vestuario y un extenso parque con rejas a la calle.

La primera etapa del Taller consistió en un ciclo de Cine-Debate con perspectiva de género; el cual tuvo como objetivo general problematizar: "cómo son narradas las feminidades y masculinidades, la maternidad, la violencia, las relaciones y los estereotipos de género, la diversidad sexual y cultural, la juventud, entre otras cuestiones, en el discurso cinematográfico" (extracto del proyecto pedagógico presentado en la Unidad Penitenciaria). Se eligió el recurso del cine porque como estudiantes de Comunicación Social, entendimos que el cine ha constituido uno de los dispositivos culturales y comunicacionales más potentes del siglo XX, y ha instaurado consigo un nuevo modo de narrar el mundo, pero también de construirlo a través de la imagen. Mediante los talleres procuramos abordar el lenguaje audiovisual y sus principales herramientas representacionales en toda su complejidad. La idea fue interrogar y debatir alrededor de un conjunto diverso de materiales de ficción -películas y series-, tomando el género como eje transversal.

Consideramos importante desde el punto de vista educativo que las discusiones/reflexiones/inquietudes surgidas a partir de las películas pudiesen quedar reflejadas en un producto comunicacional como memoria del taller. Para ello, planteamos realizar, una vez finalizada la etapa de cine-debate, un mural,

1 Este Taller forma parte del trabajo de campo de una investigación doctoral en comunicación acerca del devenir sexual en los espacios de encierro, particularmente en espacios de encierro de tipo carcelario destinados a "mujeres". Dicho trabajo a su vez se articula con un proyecto bienal de investigación y desarrollo, acreditado y financiado por la Universidad Nacional de La Plata desde el año 2015, ejecutado por el Laboratorio de Comunicación y Género de la Facultad de Periodismo y Comunicación Social, titulado "El amor romántico en las tramas de los discursos sociales: modalidades de producción y reproducción de la violencia de género". 
no como objeto estético sino fundamentalmente como hecho colectivo y estrategia comunicacional.

\section{La Escuela Popular de Género}

En un escenario nacional de avanzada de la violencia machista, pero también de mayor organización por parte de las mujeres, de proliferación de instancias organizativas en materia de género, se llevó adelante la EPG. La misma resultó de una iniciativa conjunta entre la Facultad de Periodismo y Comunicación Social de la Universidad Nacional de La Plata y la Dirección de Derechos Humanos de la localidad de Ensenada (financiada por ésta última, y enmarcada en una política pública municipal).

Se propuso en 2016 darle continuidad a una experiencia educativa denominada "Escuela Popular de Género" ${ }^{2}$, destinada a mujeres de sectores populares con inserción y/o referencia política en los barrios de Punta Lara y El Dique. Entre los meses de junio-agosto, todos los miércoles a la mañana se encontraban en el Sindicato de Trabajadores Municipales de Ensenada un grupo de mujeres cooperativistas (de la Dirección de Cooperativas del Municipio), docentes universitarias, funcionarias públicas con vinculación directa a la problemática de género, profesionales de la salud. La presencia de diferentes actores/as sociales tendió al fortalecimiento de los lazos comunitarios a través de la promoción de estrategias articulatorias con el Estado, en tanto garante de derechos, tal como lo establece la Ley Nacional de Protección Integral para Prevenir, Sancionar y Erradicar la violencia contra las mujeres.

Se trabajó con un grupo reducido pero involucrado, y en algunos casos afectado inmediatamente por la problemática de la violencia de género intrafamiliar. Los talleres estuvieron focalizados en la cuestión de la salud sexual y reproductiva, dirigidos a pensar la sexualidad y el sexo no sólo como un acto o un conjunto de actos, sino desde una perspectiva más integral relativa a la identidad de género, y desde distintos ángulos.

\section{Tensiones, rupturas y residuos en torno a "lo educativo"}

Partimos de reconocer el cruce de dos experiencias situadas en contextos contrapuestos, desde el punto de vista social y político. La institución carcelaria, regida por un compulsivo sistema de jerarquías, y fines de disciplinamiento social; y un espacio comunitario, que más allá de la asignación de roles, se funda

2 Entre 2013, 2014 y 2015 la Facultad de Periodismo y Comunicación Social participó en la coordinación de tres experiencias de Escuelas Populares de Género, en estos casos enmarcadas en una política pública implementada desde el Consejo Nacional de las Mujeres durante la gestión presidencial de Cristina Fernández de Kirchner. 
sobre la base de la horizontalidad y tiene como fin empoderar a los sujetos mediante el ejercicio de sus derechos. Más allá de los objetivos y propósitos establecidos para cada taller, los contextos de realización condicionan los procesos educativos y hacen a las posibilidades de enunciación de los sujetos.

Centraremos la mirada en cómo las mujeres que participaron de estas instancias entienden "lo educativo", desde sus lugares sociales y de género, desde sus trayectorias escolares, y desde su condición de participantes del taller. A estos fines, delineamos dos ejes de análisis: por un lado, aquellos sentidos residuales de la educación, y por el otro, aquellos sentidos rupturistas, que ponen en tensión y desestabilizan los modos establecidos de pensar y habitar "lo educativo".

\section{Sentidos residuales}

Tomamos el concepto residual de R. Williams, definido textualmente como "aquello que ha sido formado en el pasado pero todavía se halla en actividad dentro del proceso cultural; no sólo como un elemento del pasado, sino como un efectivo elemento del presente" (1988, p. 144), regulatorio de los significados, valores y prácticas culturales del presente. Un residuo vivo en tanto se reactualiza y se reafirma constantemente, haciendo perdurar de diferentes modos, sentidos y relaciones sociales dominantes, - "la hegemonía constituye siempre un proceso activo" (Williams, 1988, p. 137).

Los significados residuales respecto de la educación imprimen consigo un fuerte componente moral, y no casualmente, ya que la institución escolar tuvo una clara función social y disciplinaria relacionada con la formación de ciudadanos/as para la gran Nación Argentina. De ciudadanos/as y de mano de obra; "la disciplina aumenta las fuerzas del cuerpo en términos económicos de utilidad, y disminuye esas mismas fuerzas en términos políticos de obediencia" (Foucault, 2003, p. 83).

Esos significados y valores morales continúan demarcando nuestra matriz de pensamiento, nuestras pautas de comportamiento, nuestras percepciones del mundo y auto-percepciones, nuestros horizontes a futuro, etc.

Durante los talleres de la EPG, fueron aflorando sentidos alrededor de lo educativo -y en particular de la inserción escolar-, asociados al progreso individual; no sólo en términos económicos, sino fundamentalmente sociales, morales y espirituales. Muchas de las mujeres se referían al deseo de que sus hijos/ as estudien y salgan adelante; de algún modo, hacer lo que ellas no pudieron, no sólo por ser pobres, sino también por ser mujeres. Del total de participantes (regularmente quince), ninguna conocía la Universidad Nacional de La Plata, y sólo algunas estaban completando sus estudios secundarios gracias al programa Fines (Programa Nacional de Finalización de la Escuela Secundaria).

En sus testimonios se hacía patente el rol de la educación formal como garante del progreso individual, pero a su vez, el rol de las mujeres como garan- 
tes del proceso educativo de los/as niños/as. Una responsabilidad asignada a las familias nucleares heterosexuales, que en la práctica recae con mayor peso sobre las mujeres-madres, quienes desarrollan múltiples e invisibles tareas diarias de sostén y acompañamiento de la educación de sus hijos/as, desde ayudar con los deberes, comprar materiales, llevarlos/as a la escuela, mantener diálogo con la comunidad educativa, etc.

Algunas compañeras, las que participan orgánicamente de espacios barriales comunitarios, plantearon la necesidad del apoyo escolar para evitar que los/ as chicos/as dejen la institución, o mejor dicho, que la institución los/as deje a ellos/as.

Como madres nos tenemos que involucrar y empoderar a nuestros hijos para que puedan integrarse [...] a partir de ayudarlos con las tareas de la escuela [en el centro comunitario] pudimos llegar a otras mamás del barrio, tías, primas que los iban a dejar y volvían a buscarlos. (Cristina. Trabajadora de las cooperativas municipales de Ensenada, 10 de agosto de 2016)

En este sentido, no sólo la implicación familiar en la organización escolar está atravesada por una diferenciación y una desigualdad de género, sino también la implicación de los movimientos barriales de los cuales participan, ya que delegan la organización del apoyo escolar exclusivamente en manos de mujeres.

Por otro lado, y como mencionamos anteriormente, las mujeres no han podido completar los estudios, no menos por su condición de género que por su clase. En sus discursos la maternidad apareció intermitentemente como destino, y el acceso a la educación como un privilegio. En cuanto a las conflictividades que les significa estudiar, durante el taller abocado a las modalidades de violencia intrafamiliar, una de las compañeras -joven, de nacionalidad paraguaya y estudiante del programa Fines- comentó que a su marido no le gustaba que ella estudie, y que en más de una oportunidad la había ido a buscar hasta la puerta de la escuela. Salir a estudiar connota el poder de salir del hogar para hacer algo por ellas mismas, y no para los/as demás; ocupar el tiempo de un modo inesperado. "Los esposos se oponen a que 'sus mujeres' aprendan, tengan estudios y sean superiores a ellos en conocimientos, es la forma de ejercer el poder y el control de la dominación masculina" (Arenas, 2002, p. 115).

En cuanto a las mujeres privadas de la libertad se ven interpeladas a nivel social e institucional de un modo particular por el mandato del progreso, adquiriendo una doble impronta: la intranquilidad por el progreso de sus hijos/as y por el de ellas mismas. Los prolongados tiempos de encarcelamiento hacen visible, y urgente, la pregunta por el proyecto de vida; y la educación, en sus distintos niveles, se presenta como una vía y una demostración de progreso frente a sus familias, a sus jueces y al Servicio Penitenciario; de hecho el estímulo educativo es sumamente valorado dentro del régimen de progresividad penal. 
Mediante la incorporación a la cultura escolar, las mujeres detenidas buscan alejarse del 'hedor' que conlleva la criminalidad, para emplazarse en el imaginario de la civilización, permitiéndoles la re- constitución como ciudadanas aptas para la vida en sociedad que les espera tras cumplir sus condenas. Estudiar es aún más valorado que trabajar; supone un esfuerzo notable, por los obstáculos sistemáticos que impone el Sistema Penitenciario; constituye 'un mérito', una decisión que dará réditos en 'el afuera'. En estos contextos sociales complejos el acceso a la educación posibilita la interrupción de los destinos homogéneos determinados por las condiciones económicas, por las carencias materiales y afectivas, por la conculcación de los derechos; "es una garantía de la condición humana para las personas privadas de la libertad, una posibilidad de reducción de su vulnerabilidad social y psicológica que está profundizada a partir del encierro" (Avendaño, Ceballos \& Romero, 2015, p. 7). Sin embargo "en la práctica cotidiana no se toma a la educación como un derecho universal e inalienable, ya que acceder a la educación en este contexto singular es casi un beneficio de los/ as “buenos/as' presos/as” (Scarfó \& Zapata, 2013, p. 1).

Ella es 'un bocho's, (refiriéndose a María) la más bocho de todas acá, es la única que está estudiando una carrera universitaria, yo soy como su secretaria. (Luciana ${ }^{4}$. Participante del Taller de Cine-debate, 14 de octubre de 2016)

Habla mucho porque va a la Universidad. (Graciela. Participante del Taller de Cine-debate sobre una compañera que intervenía asiduamente en los debates. 26 de octubre de 2016)

Las compañeras que estudian suscitan admiración; por oposición, quienes no estudian y no logran rendir el tiempo 'potencialmente productivo', son vistas como afincadas en el atraso, la barbarie y el delito, retomando la educación su función social de re-inserción.

Ya que están presas tendrían que obligarlas a levantarse, que vayan a la escuela, que asuman responsabilidades. (Patricia, encargada de la biblioteca de la Unidad ${ }^{5}$, participante del Taller de Cine-debate, 15 de diciembre de 2016)

Es mediante la educación que tienen lugar los desplazamientos disciplinarios de la matriz moderna: el paso del sujeto cultural al sujeto pensante, del mero estar al 'ser alguien', de la metáfora del hedor a la pulcritud, de la confusión y el oscurantismo al 'iluminismo', del atraso al progreso, de la barbarie a la civili-

3 Expresión coloquial y popular utilizada para designar a una persona con alto coeficiente intelectual.

4 Los nombres de las compañeras detenidas, fueron modificados para preservar su identidad.

5 El cuidado de la biblioteca forma parte de los oficios que el Servicio Penitenciario Bonaerense genera para las mujeres detenidas, a cambio de un peculio simbólico, que en ninguno de los casos supera los 20 pesos mensuales. 
zación; es la edificación del ciudadano moralmente aceptado, económicamente activo y políticamente correcto. También es fundamental destacar que si bien la institución penitenciaria evalúa la progresividad penal de las personas sobre la base de la conducta y el concepto, incumple con las condiciones materiales y estructurales para el sostenimiento de los procesos educativos-escolares-académicos, que (dentro de su misma lógica) son garantía de otro tipo de progreso; el moral, social y cultural.

Yo me anoté en 'Periodismo y Análisis de sistema', sin embargo, me dijeron que al haber solo un móvil en la unidad, no me podían llevar y traer de la facu tantas veces, que tenía que elegir una de las dos carreras [...] el sistema no te deja avanzar. (Marcela, participante del Taller de Cine-debate, 26 de octubre de 2016)

Creo que la educación cambia mucho las relaciones acá adentro, reduce la violencia. Yo tengo un amigo, Jesús, que acaba de salir en libertad y su historia me emociona mucho, porque él entró siendo analfabeto y salió en la Universidad... el sistema busca quebrarnos, nos las hace difícil, incluso hace que en el medio nos peleemos y compitamos entre nosotras. (María. participante del Taller de Cine-debate, 26 de octubre de 2016)

Vale recalcar que las dificultades u obstáculos al pleno cumplimiento del derecho a la educación en contextos de encierro se profundizan en el caso de las mujeres presas. Según el relato de las compañeras, las unidades femeninas cuentan con una menor cantidad de móviles para el traslado hasta los centros de estudio que las unidades masculinas; no tienen Internet, no se les provee el material bibliográfico y tampoco se les proponen alternativas para suplirlo. También se destaca de las citas anteriores el sentido reparador que se le asigna a la educación, no sólo de las marcas que imprime la violencia institucional y de género en la subjetividad de cada mujer, sino del tejido colectivo, y su componente insoslayable de solidaridad y sororidad.

Si bien las propuestas pedagógicas de ambas experiencias fueron elaboradas desde una perspectiva crítica, se pudieron evidenciar en distintos momentos de los procesos las marcas de la escolarización presentes de manera naturalizada en las mujeres. El dialogo de saberes fue la modalidad de trabajo vertebral de ambas propuestas; sin embargo, en determinadas instancias, parecían demandar la transmisión de un saber "verdadero" sobre los temas tratados, lo que daba cuenta de que se sentían evaluadas y que sus propios saberes no eran válidos para ser compartidos. La cultura bancaria ha calado tan hondo en las subjetividades, que frente a propuestas alternativas de educación, basadas en el diálogo, se carece de una pre-disposición al aprendizaje por parte de los sujetos. Las experiencias que traen parecen no tener status de saberes legítimos. En el caso de la EPG, cuando hablaba una compañera, era común que no se la escuchara, que se interrumpieran, que se dispersaran. Contrariamente, cuando nos tocaba hablar a las coordinadoras o las invitadas (recibimos la visita de una médica, 
una psicóloga y una abogada) se notaba otra escucha, más atenta y focalizada. En el Taller en la Unidad 8, luego de mirar una película, cuando llegaba la instancia del debate, la opinión de las coordinadoras "parecía valer más" que las suyas. Otro denominador común, fue que las mujeres consultaban sobre la cantidad de ausentes que podían tener para continuar siendo "regulares".

Por último, la certificación del tránsito por ambos espacios, puso de relieve la necesidad de formalizar y dar a conocer frente a otros/as la culminación de un proceso educativo. En el caso de la Escuela, representó la obtención de un logro reconocido por instituciones del Estado; en el caso del Taller en la Unidad 8 , la obtención de un documento que podría acortarles sus condenas. Más allá del valor judicial que reviste la acreditación de "un saber" para quienes están privadas de su libertad, el momento de la entrega de certificados no dejó de ser significativo y emotivo para todas.

Saqué los certificados. Julita hizo una lista con los nombres de las que habían participado. Averiguaron los DNI. Los terminé completando yo porque ellas decían que no tenían buena letra. [...] La encargada [penitenciaria] de ese momento dijo que su superior le había dejado dicho que saque unas fotos con los certificados y se las envíe [...] algunas se fueron a arreglar para la foto. Julia hizo un chiste en relación a que ella justo se había planchado el pelo a la mañana. (Registro de campo, Módulo UP N8, 9 de diciembre de 2016)

\section{Sentidos rupturistas}

Los sentidos sobre educación que llamamos 'rupturistas' son aquellos que se vinculan fundamentalmente al paso de las mujeres por cada uno de los espacios de taller. Concretamente a los sentidos alejados del pensamiento binario que imprimen los modelos educativos tradicionales; progreso-atraso, hedor-pulcritud, culto-inculto, entre otros tantos. Vale señalar que las mujeres suelen ocupar lugares de otredad dentro de la otredad en el marco de estas construcciones binarias. Si desde la mirada hegemónica en los sectores populares se condensa el atraso, el hedor, la falta de educación y de cultura, en las mujeres pobres se concentra todas las formas imaginables de estigma y violencia.

Sin embargo, en el caso de la EPG y mediante el compromiso que las compañeras demostraron, se corrieron del lugar de reproducción social y sexual que simboliza el hogar, para reubicarse en un lugar nuevo, de producción, creación y de encuentro con otras mujeres.

Me gustó cómo nos enseñan y cómo nos explican que cada una aporta sobre lo que siente que es la violencia y eso también enseña a las demás. (Yamila, Trabajadora en la cooperativa municipal de Ensenada, 14 de agosto de 2016) 
Del taller me llevo lo mejor. El compromiso con mis compañeras que son todas excelentes personas y compañeras con las que compartí mate y buenos momentos. (Luisa. Vecina de Ensenada. Acompañante de víctimas de violencia de género en el barrio, 14 de agosto de 2016)

El entusiasmo del grupo de mujeres de la EPG se dejaba entrever a través de su puntualidad. Pese a que el taller comenzaba muy temprano en la mañana, cuando las coordinadoras llegábamos al lugar, la mayoría de ellas nos estaba esperando. Muchas veces iban con sus hijos/as, e incluso asistieron una mañana luego de una tormenta fuerte que había inundado sus barrios, y en algunos casos sus casas.

Más allá de los residuos de la cultura machista, patriarcal y liberal que permea los sentidos y prácticas de educación, las mujeres transgredieron lo "pre-fijado" para ellas. La potencia política de esos encuentros con otras compañeras, de esos mates, de esas charlas y de esos abrazos, imprimieron a la EPG un sentido disruptivo de sus cotidianeidades, de los modos cotidianos de vincularse con otros, y en especial con otras. No fueron sólo sus voces, sino sus cuerpos lo que pusieron en juego; cuerpos que encarnan historias de exclusiones y opresiones; cuerpos que entramados a los de otras mujeres produjeron efectos de transformación al representar otra historia posible, y plural. "Una pluralidad de historias, de la que nace la posibilidad de una utopía” (Sousa Santos, 2011, p. 20).

Acá está bueno porque nos sacamos los prejuicios, podemos hablar de cosas que por ahí en otros lugares o con otras personas no podemos hablar, cosas que nos pasan a todas. (Rosario. Vecina de Ensenada, 15 de junio de 2016)

En cuanto al Taller en la Unidad 8, es necesario tener en cuenta que la vida de las personas que viven el encierro está siendo narrada por otros/as: jueces, agentes del servicio penitenciario, trabajadores/as sociales, organismos de derechos humanos, etc. Todas aquellas propuestas educativas que trabajan desde una perspectiva dialógica, que persiguen el libre pronunciamiento y el estímulo a la reflexividad de los sujetos, están favoreciendo a la ruptura de esa inercia que les mancilla la voz, y por la cual han sido históricamente hablados y habladas. Nuestro taller se configuró como un espacio en el que ellas eran protagonistas y dueñas de sus voces: elegían entre todas las películas que íbamos a ver, preparaban la sala para proyectar, debatían, manifestaban cuando una película no les gustaba. Tomaron lugar sentidos relacionados con la solidaridad, la organización colectiva, el interés por la vida de la otra (sobre todo cuando en el marco de los debates contaban anécdotas personales), en otras palabras, la educación apareció como un puente y una condición de posibilidad de encuentro con otras.

6 Desde el siguiente link se podrá acceder a los testimonios de las mujeres respecto de su paso de la experiencia de la EPG, ver http://bit.ly/2wmVAuB. 
Los dos talleres concluyeron con la elaboración de un producto comunicacional a los fines de que queden registradas algunas dimensiones de sus recorridos subjetivos, sus posicionamientos, sus críticas, las sensaciones producidas, las eventuales re-significaciones del género, y de sí mismas.

En el Taller de Comunicación, Arte y Género realizamos un mural, bajo la coordinación de Carolina (muralista). Ellas querían a toda costa que el mural sea visible para el afuera, así que eligieron una pared ubicada en un sector entre la calle y la puerta de entrada al módulo, en una especie de patio interno. Sin embargo, la definición del lugar fue parte de la negociación con el Servicio Penitenciario, pero sobre todo el contenido del mural; el boceto debió ser previamente evaluado y aprobado por las autoridades penitenciarias. Tampoco fue tarea fácil acordar entre todas ellas el concepto del mural. Había coincidencia en cuanto a representar la idea de libertad, no así en cuanto a qué frase, dibujo, color la simbolizaba. Por ello el mural intentó contener los múltiples representaciones que fueron surgiendo asociadas con la libertad: niños/as jugando en un parque, una paloma en una jaula abierta, una chica en una playa levantando los brazos, un arco iris.

En el caso de la EPG realizamos un video en el cual las mujeres narraban en primera persona qué se llevaban con ellas luego de la Escuela, cómo se habían sentido a lo largo del proceso y qué podían transmitirle a su comunidad. Les avisamos, previamente a filmar, que el video sería transmitido por un canal de aire local de Ensenada, ya que la Escuela era parte de una política pública del municipio que debía ser difundida. El hacer público el material generó nervios y expectativas frente al desafío de hablar en cámara, de poner la voz de otra manera, de contar una experiencia.

De esta experiencia me llevo aprendizaje [...] entendí qué es la violencia de género. Me llevo compañeras muy buenas. (Gladys, Promotora de Salud del barrio de Ensenada, 14 de agosto de 2016)

Para finalizar, vale mencionar que la reacción inicial frente a la propuesta de realizar estos productos fue similar y tendió al "no podemos, no sabemos, no nos animamos". No obstante, la vergüenza, la inseguridad, la resistencia y la percepción introyectada de que son incapaces de hacer y de decir, fue cediendo paso al juego y las risas, al concebir que lo de menos era el uso de la técnica y que no había una forma única o correcta de grabar un video, o de pintar un mural. El día del rodaje casi todas quisieron aparecer en cámara, les gustaba el hecho saber que iban a ser vistas por sus familias; en la cárcel, la totalidad de las compañeras que viven en el módulo, participantes o no del taller, se involucraron activamente con el proyecto del mural, desde solicitar los materiales al Servicio, hasta pintar y limpiar. 


\section{Conclusiones}

La imbricación de la comunicación, la educación y el género en tanto umbral para el análisis social, no preestablece en lo más mínimo los contenidos, lugares de intervención o el tipo de sujetos/as a investigar. Pero sí guía la pregunta con la que vamos a interrogar una determinada realidad. Como muestra de ello, para este trabajo tomamos dos talleres anclados en campos materiales antagónicos en términos políticos e ideológicos. Atravesamos una misma mirada por el bien-llamado 'sistema de la crueldad' que caracteriza al régimen de vida intra-muros, y por las escenas matutinas, de mates y conversaciones colectivas, que dieron vida a los talleres de la Escuela Popular de Género.

A pesar de la modalidad criminógena en que se ejerce el poder en los contextos de encierro, de las múltiples expresiones de violencia que están habilitadas y de la reproducción de sentidos sociales y educativos residuales, también es posible desde allí gestar espacios donde tejer otros lazos y formas de circulación del poder. A diferencia de los enfoques de corte político que describen la cárcel como una institución unívocamente coercitiva, el análisis y las intervenciones desde comunicación/ educación abandonan esta figuración monolítica, que petrifica la capacidad de agenciamiento de los sujetos que por ella transcurren, para adentrarse, recuperar y comprender los entramados de poder, la irreductible dimensión de las luchas por el sentido y las resistencias. El Taller de Comunicación, Arte y Género ha sido posible gracias a una mirada táctica de los clivajes institucionales, constituyéndose como un espacio prolífero de sentidos rupturistas de la educación y mediante la educación.

En cuanto a la realidad de las mujeres que participaron de las Escuelas Populares de Género, si bien no viven entre muros, están atravesadas por contextos sociales y económicos que producen otras formas de violencia y vulneración de derechos; el ejercicio del poder asume otros rasgos, modalidades e intensidades, y por lo tanto, las otras formas de resistencia. Los talleres se configuraron teniendo en cuenta estos condicionamientos "del medio libre", sumado a la cualidad de inscribirse en una política pública municipal lo cual orientó el tratamiento del género hacia un lugar preciso (la perspectiva de derechos, las normativas vigentes, el rol de las instituciones, etc); pero manteniendo firme la necesidad de problematizar (y transformar) colectivamente los sentidos y las prácticas hegemónicas. Sin embargo, más allá de las intencionalidades políticas que puedan prefijarse a una práctica educativa y de los esfuerzos en consumar esos propósitos; nunca podremos asegurarnos la interpelación de los/as sujetos/as, y está bien que así sea.

Es importante subrayar que los sentidos residuales en torno a "lo educativo" también deben ser mirados desde una perspectiva de género y no soslayados de los sentidos residuales respecto del género y las sexualidades. El proyecto nacional que trajo consigo un proyecto de ciudadanía, también imaginó un sujeto social femenino y masculino. Al establecer el hogar como lugar natural de las 
mujeres, se las privó de su participación en las esferas educativas y se las predestinó a un estado de mayor pobreza social, cultural, intelectual y económica que los varones. Si bien a lo largo de los talleres identificamos la vigencia de estos sentidos, también leímos el compromiso con los espacios educativos propuestos en clave política como principio de un malestar respecto de esas sujeciones de género, y de un bienestar saliendo del hogar por un rato, re-pensándose junta a otras.

Para finalizar, queremos recalcar la importancia de que la relación entre comunicación, educación y género no sólo se instaure como pregunta epistemológica en el plano de la investigaciones académicas, sino también en el plano de la formulación y gestión de políticas universitarias, y del trabajo en territorios; deviniendo urgente otra pregunta relacionada con los modos de relación y aportes recíprocos entre la Universidad y el conjunto de la sociedad. Siempre y ante todo, haciendo eje en la productividad y potencialidad política con que cargan los saberes vinculados al género para la democratización de la Universidad pública, y de otros ámbitos.

\section{Referencias bibliográficas}

Álvarez Álvarez, C. (2008). La etnografía como modelo de investigación en educación. Gazeta de Antropología. 24, (1). 1-15.

Arenas, G. (2002). Las madres en la educación, una voz siempre presente pero, ¿reconocida?. En M. Á. Santos Guerra (Coord.) El harén pedagógico: perspectiva de género en la organización escolar. (pp. 103-118). España; Editorial Graó.

Avendaño, C.F, Ceballos, C.E \& Romero Ramayo, M.A (2015). Comunicación y educación: resignificación de prácticas y experiencias en contextos de encierro. Caso: Servicio Penitenciario de Córdoba, Establecimiento No 5 Villa María. VIII Seminario Regional (Cono Sur) ALAIC. Córdoba. Recuperado de http:// bit.ly/2wqTKHl.

Buenfil Burgos, R. N. (1992). Análisis de discurso y educación. México: DIE.

Cano, A. (2012). La metodología de taller en los procesos de educación popular. Red Latinoamericana de Metodología de las Ciencias Sociales (ReLMeCS), 2 (2). 22-52. Recuperado de http://bit.ly/2emHD5O.

Cremona, M. F. (2013). Género, Mujeres, niños y niñas con discapacidad. Revista "Discapacidad, Justicia y Estado". Buenos Aires: Editorial INFOJUS.

Cremona, M. F. (2016). La articulación educación, comunicación y género. Documento de Cátedra. Comunicación y Educación Cátedra II. La Plata: Editorial Facultad de Periodismo y Comunicación Social.

Fernández, A. M. \& Siqueira Peres, W. (2013). La diferencia desquiciada. Buenos Aires: Biblos.

Foucault, M. (2003) Vigilar y castigar. Nacimiento de la prisión. Buenos Aires: Siglo XXI Editores. 
Guber, R. (2011). La observación participante como sistema de contextualización de los métodos etnográficos: La investigación de campo de Esther Hermitte en los Altos de Chiapas. Revista Latinoamericana de Metodología de las Ciencias Sociales. 2 (1), 60-9o.

Huergo, J. (2003). Lo que articula lo educativo en las prácticas socioculturales. Resistencia, Chaco: INCUPO.

Martin Barbero, J. (2012). De la comunicación a la cultura. Perder el "objeto" para ganar el proceso. Signo y Pensamiento, 60 (30), pp. 76 - 84.

Ortiz, R. (2004). Taquigrafiando lo social. Buenos Aires: Siglo XXI Editores.

Sautu, R. (2005). Todo es teoría: objetivos y métodos de investigación. Buenos Aires: Lumiere.

Scarfó, F. \& Zapata, N. (2013). Obstáculos en la realización del derecho a la educación en cárceles. Una aproximación sobre la realidad Argentina. Cátedra UNESCO de investigación aplicada para la educación en la cárcel, Montreal, Canadá.

Scott, J. (1996). El género: una categoría útil para el análisis histórico. En, M. Lamas (Comp.) El género: la construcción cultural de la diferencia sexual (pp. 270-296) México D.F: PUEG-UNAM.

Sousa Santos, B.B (2011). Epistemologías del sur. Utopía y Praxis Latinoamerica. Revista Internacional de Filosofía Iberoamericana y Teoría Social. 54 . 17 - 39.

Vassallo de Lopes, M. I. (2012). La investigación de la comunicación: cuestiones epistemológicas, teóricas y metodológicas. Revista Diálogos de la Comunicación (FELAFACS). pp. 12-27.

Williams, R. (1988). Marxismo y literatura. Barcelona: Editorial Península 